\title{
Sciuridae, Rapoport's effect and the mismatch between range size, conservation needs, and scientific productivity: an approach at the genus level
}

\author{
Giovanni Amori, Spartaco Gippoliti, Luca Luiselli and Corrado Battisti
}

Amori, G., Gippoliti, S., Luiselli, L. and Battisti, C. 2009. Sciuridae, Rapoport's effect and the mismatch between range size, conservation needs, and scientific productivity: an approach at the genus level. - Web Ecol. 9: 1-7.

\begin{abstract}
Rapoport's rule states that species at high latitudes have broader ranges than species at low latitudes. This rule has been strongly disputed over the years, and the majority of current scientists think that this is mostly a local phenomenon. However, if Rapoport's rule applies, it should be a priori expected that taxa occurring in equatorial and tropical regions should be more threatened than those at temperate regions. In this paper, we test 1 ) whether Rapoport's rule applies to Sciuridae genera (Mammalia, Rodentia) and, if so, 2) whether the research efforts by scientists have been concentrated on those taxa that, because of their range size, may be predicted to be more threatened (i.e. equatorial and tropical taxa). Distribution data on Sciuridae came from literature and were transformed as maps according to World Map Program, and data about number of papers published by genus and by latitude were collected from the ISI Web of Knowledge. Our analysis verified the occurrence of a Rapoport's effect in Sciuridae in both the hemispheres: mean range size increased significantly with latitude increases in both hemispheres. However, literature data inspection revealed that only a few genera accounted for the great majority of studies, and these genera were widely distributed and found at high latitudes. Thus, there is a potentially serious gap between current knowledge and threat expectations for Sciuridae worldwide. We therefore strongly urge scientists to give priority attention towards field studies of tropical Sciuridae genera.
\end{abstract}

G.Amori (giovanni.amori@uniroma1.it), CNR Insitute of Ecosystem Studies, via A. Borelli 50, IT-00161 Rome, Italy. - S. Gippoliti, Italian Inst. of Anthropology, piazzale Aldo Moro 5, IT-00185 Rome, Italy. - L. Luiselli, Centre of Environmental Studies Demetra s.r.l., via Olona 7, IT-00198 Rome, Italy. - C. Battisti, Conservation Nature Office, Environmental Service, Province of Rome, via Tiburtina 691, IT-00159 Rome, Italy.

Rapoport's rule states that species at high latitudes have broader ranges than species at low latitudes (Stevens 1989). This idea has been strongly debated, with many studies failing to find support for the rule (and when they do it is often over fairly narrow latitudinal spans) (Gaston and Chown 1999), so that it has been downgraded from a 'rule' to an 'effect' (Gaston et al. 1998, but see Taylor and Gaines 1999). However, the Rapoport's effect has been confirmed for at least some groups of organisms (Gaston et al. 1998). In most previous tests of the Rapoport's effect, scientists based their conclusions on a statistical onedimensional approach of analysis that uses scatter plots to show the latitudinal variation in range size over latitudinal bands, across individual taxa or have analysed changes in the latitude-range size association with time through phylogenetic comparative analysis. These approaches may 
convey important information, but may be limited to some extent by the fact that they lack a truly geographical perspective to directly map the mean variation of range size over continents (Ruggiero and Werenkraut 2007 for a synthesis, and for some specific cases: Smith et al. 1994, Eeley and Foley 1999, Noonan 1999, Graves and Rahbek 2005, Hawkins and Diniz-Filho 2006, Orme et al. 2006). Thus, as pointed out by Ruggiero and Werenkraut (2007), "most of the analyses of range size patterns that tested the Rapoport's effect are impregnated by the imprint of thinking in one 'latitudinal' dimension". According to some authors, many factors act against the rule (biotic and abiotic factors or others linked to the evolutionary age of the species, different at different latitudes; Rohde 1996, Gaston et al. 1998). Nevertheless, recent reports for specific groups suggest that the rule may still matter, at least for specific contexts and taxonomically and ecologically-related groups, also after controlling for phylogenetic effects (Diniz-Filho and Tôrres 2002), although ecological and geometrical constraints around the world could influence it (Ribas and Schoereder 2006). Within this complex context, it is obvious that we need to study additional groups of organisms, and by applying several methods of analysis, in order to understand how exactly does Rapoport's effect matter, and how we may improve our perception of the pattern (Lyons and Willig 1997, Blackburn and Gaston 2006).

Mean range size could be considered as an indirect conservation status indicator because one would expect that small range sizes would characterize endemic taxa which may be more threatened (Gaston and Blackburn 1996, Arita et al. 1997, Mace et al. 2001). Thus, it should be expected a priori that species in equatorial and tropical regions will be more threatened than those at temperate regions as a consequence of the Rapoport's effect. Thus, it would in theory be possible to 'organize' the scientific research on specific taxa in relation to their conservation needs, for instance by concentrating the efforts to study within larger taxonomic groups (e.g. families or orders) the ecology and behaviour of those single species/genera that occur in equatorial and tropical areas. However, to our knowledge, testing the occurrence of a Rapoport's effect matching with the 'geographic origin' of field research efforts has never been done in the international literature, particularly for any vertebrate group (Pagel et al. 1991).

In this paper, we use a particular mammalian group, squirrels (the rodents belonging to the Sciuridae family) as a case study. We test whether these animals follow the Rapoport's rule in their worldwide distribution, and if so, whether the research efforts by scientists have been concentrated on those taxa that, because of their range size, may be predicted to be more threatened (i.e. tropical taxa). In order to address these issues, we performed our analyses at the genus level (Amori and Gippoliti 2001, 2003). The reasons for selecting Sciuridae taxa as study system are multifaceted: the family Sciuridae is: 1) species-rich (it comprises nearly 280 species belonging to 51 genera); 2) offers a good opportunity to make biodiversity analysis in a broad sense because its taxonomy is quite stable, especially at the genus level (in-between the twelve years spanned between the publication of the two mammal world checklists (1993 to 2005) the number of known species for Sciuridae increased only by two, Amori and Gippoliti 2003); and 3) is particularly suitable for studying latitudinal patterns because these rodents are non-migratory and migration may obviously distort latitudinal patterns (Rabenold 1992). In this regard, it should be mentioned that, although most studies on Rapoport's effect have focused on species, there were a few studies, e.g. on plants and brachiopods, that were focused at both genera and family levels (Powell 2007). Using genera within species-rich taxa (as are rodents) may have multiple advantages. Firstly, genera were found to predict species richness distributions most closely, with higher taxa (families, orders, subclasses) exhibiting progressively worse correlations (La Ferla et al. 2002, Baldi 2003). Secondly, the geographic ranges appear more firmly established all over the planet compared to species, while the information quality on species' ranges may greatly differ among different regions. Furthermore, we suspect that the relative taxonomic stability for Sciuridae species, despite the recent turmoil in mammalian taxonomy, may reflect a lack of research on alpha-taxonomy more than a true pattern, this being untrue as for genera (Gippoliti and Amori 2007).

\section{Material and methods}

Distribution data for each genus of Sciuridae were obtained from the literature. The following literature entries were examined: Wells and Giacalone (1985), Eisenberg (1989), Emmons and Feer (1990), Corbet and Hill (1992), Gharaibeh and Jones (1996), Thorington et al. (1996), Kingdon (1997), Reid (1997), Grubb et al. (1998), Panteleyev (1998), Zahler and Karim (1998), Wilson and Reeder (2005). The distribution maps presented in the above-mentioned literature entries were utilized to create the electronic maps of the software World Map Program (hereafter WMP, Williams 2001). Geographic coordinates for the various maps were obtained by using the appropriate module in WMP. The utilization of WMP is particularly appropriate for this type of study because it subdivides the world into cells of a same surface (Williams 2001), thus allowing for easy comparisons among taxa and regions that would not have been possible with traditional UTM grids. In WMP, the two hemispheres were subdivided from north to south into 23 latitudinal bands (hereafter, LB), each one comprising a 10 ' latitudinal arc and formed by a set of cells of the same latitude (equal area grid; 36 columns $\times 24$ rows $=864$ cells of equal area each $611000 \mathrm{~km}^{2}$ wide (Williams 2001). A binary matrix (latitude/genera richness) was obtained on 
the basis of the distribution maps of the various genera, and the total number of cells occupied by the range of a given taxon were considered as indicators of total range size for each genus. In order to avoid the statistical difficulty that a same taxon may be included several times in different latitudinal bands generating non-independent data (Rohde et al. 1993), we used Rohde et al.'s (1993) method that was originally applied to analyze latitudinal ranges of fish species. These authors used the means of ranges of all species with a midpoint in the same 5-degrees LB plotted against latitude. We acquired data only for LB that host at least one record of a genus for the following range: from 0 to 71 latitude north and from 0 to -60 latitude south. For each LB we obtained the total number of genera. In WMP, each LB host a different number of cells. Consequently, the total number of genera in each LB was influenced by the different number of cells. Thus, we normalized the data to available size area. In order to do this, we calculated the 'genera density' as the ratio between the number of genera present in each LB and their relative number of squares. Then, genera density of each LB was correlated with LB latitude. We calculated, for each LB, the ratio 'genera richness of each guilds/total genera richness', correlating this value to latitude (Amori et al. 2009). Variables were compared performing a non-parametric statistic (Spearman rank correlation test, 2-tailed).

In order to analyse whether mean range size was influenced by latitude, we regressed the latitude against the mean value of the individual range sizes of the various genera occurring at that given latitudinal band. This procedure was repeated for both the Northern and for the Southern hemispheres. Then, we applied a full Monte Carlo randomization procedure (30 000 iterations) to the regression analysis by using EcoSim software (Gotelli and Entsminger 2002) to verify whether these relationships were due to chance.

In order to study the variation of scientific attention by taxon, we searched from the ISI Web of Knowledge, genus by genus, all the literature published in the various research fields, with a search for the following key-words: ecology, biogeography, taxonomy, and conservation (years 1996-2008). Then, we subdivided the world into five wide latitudinal bands (band 1: from $71^{\circ} \mathrm{N}$ to $43^{\circ} \mathrm{N}$, band 2: from $42^{\circ} 59^{\prime} \mathrm{N}$ to $20^{\circ} \mathrm{N}$, band 3: from $19^{\circ} 59^{\prime} \mathrm{N}$ to $0^{\circ}$, band 4: from $0^{\circ}$ to $20^{\circ} \mathrm{S}$, and band 5: from $20^{\circ} 01^{\prime} \mathrm{S}$ to $43^{\circ} \mathrm{S}$ ), and assigned each Sciuridae genus to one or more latitudinal bands. For instance, the genus Sciurus is occurring from approximately $60^{\circ} \mathrm{N}$ and $25^{\circ} \mathrm{N}$, covering both latitudinal bands 1 and 2, being scored in the group ' 12 ' in the statistical analyses (Table 1). Then, the variation in the numbers of studies published by latitudinal band group was analysed by one-way ANOVA (with the number of studies as dependent variable and latitudinal bands as grouping variable), followed by Tukey's Honestly Significance post-hoc test for assigning a pairwise significance among the various latitudinal bands.

\section{Results}

\section{Do Sciuridae follow Rapoport's rule?}

In the northern hemisphere, mean range size increased significantly with latitude increases (Fig. 1), and this pattern was not randomly generated after randomization tests

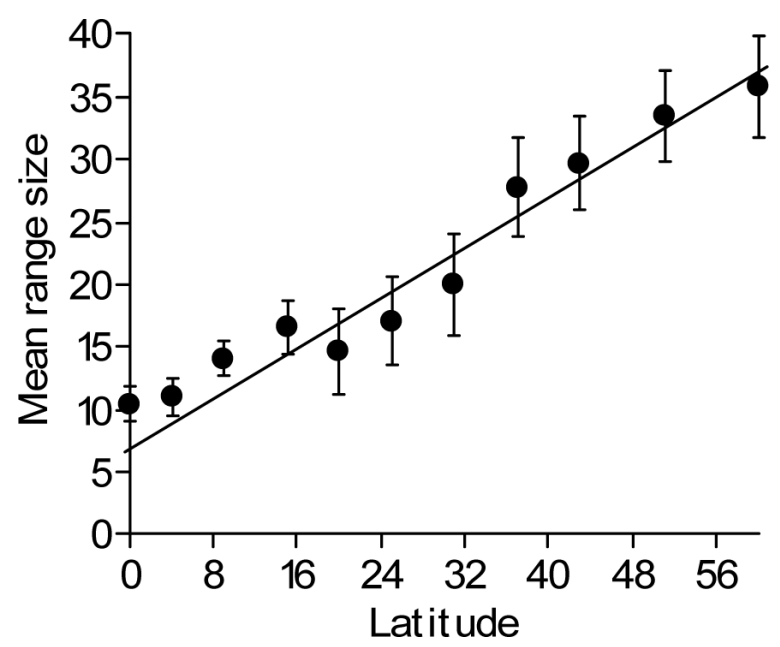

Figure 1. Relationships between latitude ( $\mathrm{x}$-axis, in $\left.{ }^{\circ} \mathrm{N}\right)$ and mean range size (y-axis, in number of cells) for Sciuridae genera in the Northern hemisphere. Statistics of the regression: $r=0.949$, mean range $=0.456$ latitude +8.64 . Error bars are given for each data point.

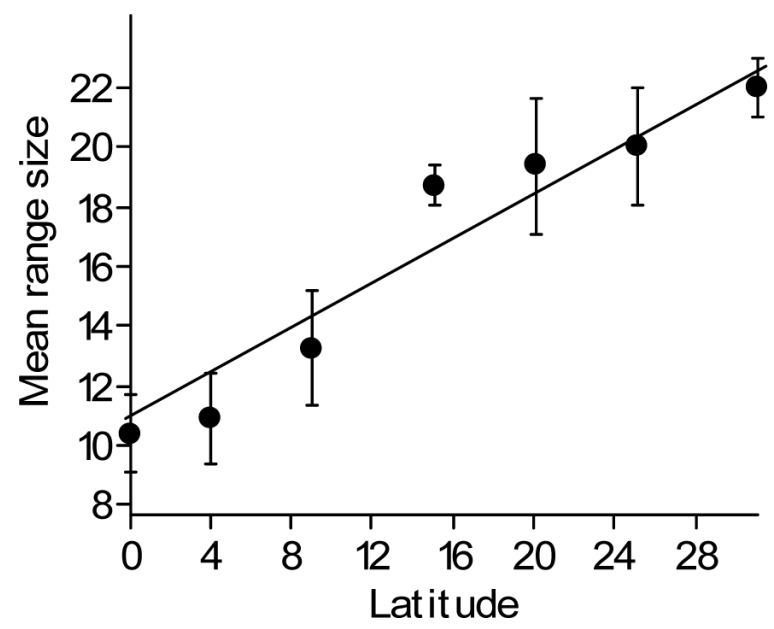

Figure 2. Relationships between latitude ( $\mathrm{x}$-axis, in ${ }^{\circ} \mathrm{S}$ ) and mean range size for Sciuridae genera in the Southern hemisphere (yaxis, in number of cells). Statistics of the regression: $r=0.967$, mean range $=0.409$ latitude +10.25 . Error bars are given for each data point. 


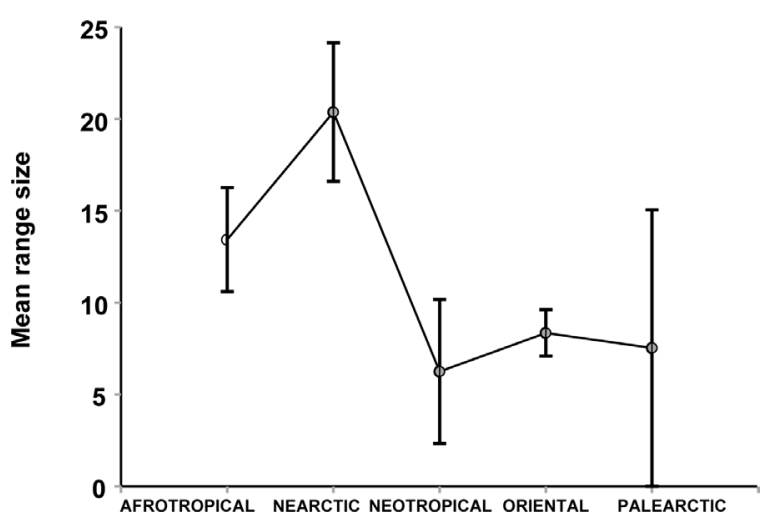

Figure 3. Mean range size (and dispersion measure, SD) for Sciuridae genera in the various biogeographic regions. For statistical details, see the text.

with Monte Carlo regression procedure (30 000 iterations, $\mathrm{p}<0.001)$. In the southern hemisphere, mean range size was also significantly influenced by latitude (Fig. 2), tending to increase with latitude increases (randomization test with Monte Carlo regression procedure after 30000 iterations: $\mathrm{p}<0.05$ ). The non-random patterns in both hemispheres clearly supported a Rapoport's effect for Sciuridae genera. However, an analysis of co-variance (ANCOVA) revealed that the slopes of the regressions were significantly different $(\mathrm{F}=34.621, \mathrm{p}<0.01)$, thus showing that the strength of the relationship was greater in the northern hemisphere.

In terms of mean range size, there were significant differences among Sciuridae genera from the various biogeographic regions (Fig. 3). More precisely, a Monte Carlo ANOVA procedure (with 30000 iterations) revealed that, once the relative size of each cell area was taken into account, 1) Nearctic genera had a mean range size significantly wider than that of Afrotropical genera $(\mathrm{p}<0.05)$ and of all the genera occurring in the other biogeographic regions ( $p<0.0001)$; 2) Afrotropical genera had a significantly wider range size than all the genera occurring in the other biogeographic regions $(\mathrm{p}<0.001)$; 3 ) genera from

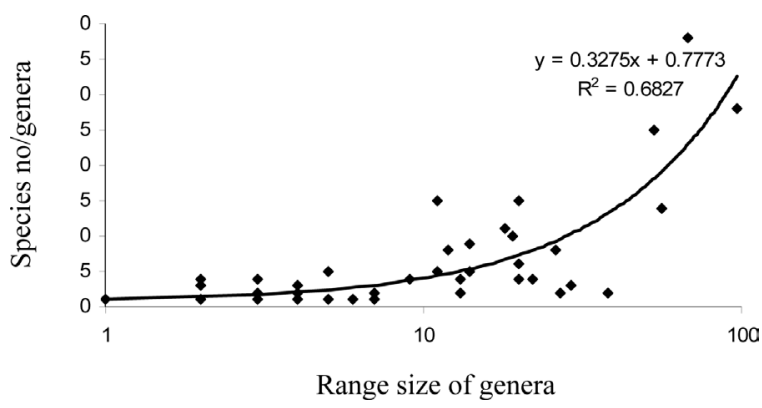

Figure 4. Relationships between (log) range size of genera and species number/genera ratio for Scuridae worldwide.

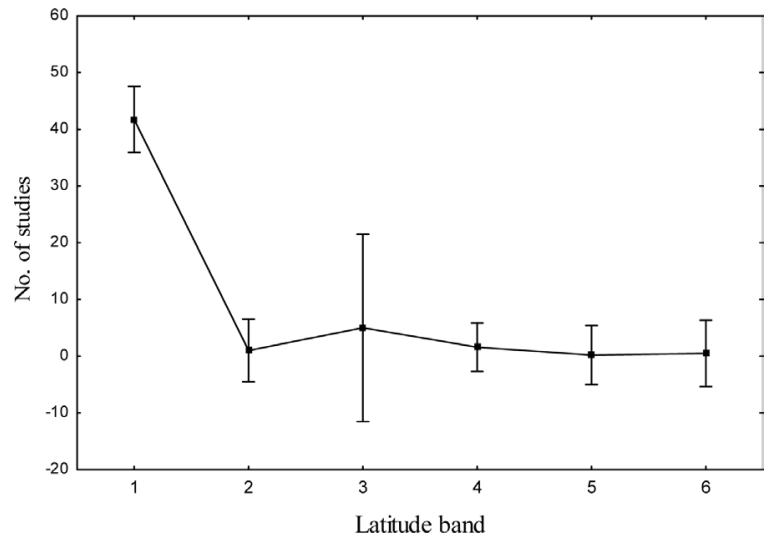

Figure 5. Distribution of the number of studies by latitudinal band. Symbols for the latitudinal bands: band 1: from $71^{\circ} \mathrm{N}$ to $43^{\circ} \mathrm{N}$, band 2: from $42^{\circ} 59^{\prime} \mathrm{N}$ to $20^{\circ} \mathrm{N}$, band 3: from $19^{\circ} 59^{\prime} \mathrm{N}$ to $0^{\circ}$, and band 4 : from $0^{\circ}$ to $20^{\circ} \mathrm{S}$. When more than one band is involved (i.e. $1-2,2-3$, etc.), this means that the given genus occurs in both latitudinal bands.

Neotropical, Oriental, and Palearctic regions were not significantly different from one another (at least $\mathrm{p}>0.278$ in the pairwise comparisons). However, as a general rule the more speciose a genus, the wider its range size (Fig. 4). The three genera with widest range size were Spermophilus, Sciurus, and Tamias, and these genera were also among the most speciose.

\section{Is scientific attention to Sciuridae genera mirroring conservation auspices collected from Rapoport's effect?}

With Sciuridae, we should expect that the genera needing higher conservation attention live around the equator, because this rodent family follows Rapoport's rule (above). Indeed, a previous study based on IUCN's criteria for assessing threatened species found that the majority of threatened genera are tropical (Amori and Gippoliti 2003). Our compilation of literature data for the various genera however revealed that only a few genera accounted for the great majority of studies, and these genera were widely distributed, and found at high latitudes (Table 1). Indeed, an ANOVA indicated that there were strong variations among geographic zones in terms of number of studies published in ISI journals (one-way ANOVA $-\mathrm{F}_{5,45}$ $=33.31, \mathrm{p}<0.00001$ ), and a Tukey HSD post-hoc test revealed that the genera at the latitudinal regions 3 (from 0 to $20^{\circ} \mathrm{N}$ ) and $3-4$ (from $20^{\circ} \mathrm{S}$ to $20^{\circ} \mathrm{N}$ ) were significantly less studied $(\mathrm{p}<0.00001)$ than those at the regions $1-2$ (from $20^{\circ}$ to $71^{\circ} \mathrm{N}$ ) (Fig. 5). Thus, this analysis confirmed that there was a gap between the regions with the highest number of genera (and the narrowest mean range size) and the 'hotspots' of scientific research. 
Table 1. Summary of the studies concerning the biology of Sciuridae genera obtained from ISI Web of Knowledge. Symbols for the latitudinal bands: band 1: from $71^{\circ} \mathrm{N}$ to $43^{\circ} \mathrm{N}$, band 2: from $42^{\circ} 59^{\prime} \mathrm{N}$ to $20^{\circ} \mathrm{N}$, band 3: from $19^{\circ} 59^{\prime} \mathrm{N}$ to $0^{\circ}$, and band 4: from $0^{\circ}$ to $20^{\circ} \mathrm{S}$. When more than one band is involved (i.e. 12, 23, etc), this means that the given genus occurs in both latitudinal bands.

\begin{tabular}{|c|c|c|c|c|c|c|}
\hline Genera & Ecology & Taxonomy & Biogeography & Conservation & Total no. of studies & Latitudinal bands \\
\hline Spermophilus & 27 & 2 & 3 & 21 & 53 & $1-2$ \\
\hline Sciurus & 32 & 4 & 6 & 37 & 79 & $1-2$ \\
\hline Marmota & 15 & 2 & 4 & 12 & 33 & $1-2$ \\
\hline Tamias & 24 & 2 & 2 & 7 & 35 & $1-2$ \\
\hline Tamiasciurus & 14 & 2 & 5 & 6 & 27 & $1-2$ \\
\hline Cynomys & 26 & 2 & 3 & 27 & 58 & 2 \\
\hline Glaucomys & 12 & 4 & 8 & 11 & 35 & $1-2$ \\
\hline Funambulus & 0 & 0 & 0 & 0 & 0 & 3 \\
\hline Pteromys & 5 & 1 & 2 & 6 & 14 & $1-2$ \\
\hline Callosciurus & 0 & 1 & 0 & 1 & 2 & 3 \\
\hline Petaurista & 1 & 2 & 1 & 3 & 7 & 3 \\
\hline Ammospermophilus & 3 & 1 & 1 & 1 & 6 & 2 \\
\hline Xerus & 2 & 0 & 3 & 0 & 5 & $4-5$ \\
\hline Atlantoxerus & 0 & 0 & 0 & 0 & 0 & 2 \\
\hline Ratufa & 1 & 1 & 0 & 2 & 4 & 3 \\
\hline Belomys & 0 & 1 & 2 & 0 & 3 & 3 \\
\hline Eupetaurus & 1 & 0 & 1 & 0 & 2 & 2 \\
\hline Menetes & 0 & 1 & 0 & 1 & 2 & 3 \\
\hline Hylopetes & 0 & 1 & 1 & 0 & 2 & $2-3$ \\
\hline Microsciurus & 0 & 1 & 0 & 0 & 1 & 3 \\
\hline Funisciurus & 0 & 0 & 0 & 0 & 0 & $3-4$ \\
\hline Paraxerus & 0 & 0 & 0 & 0 & 0 & 4 \\
\hline Tamiops & 0 & 1 & 0 & 1 & 2 & 3 \\
\hline Trogopterus & 0 & 0 & 1 & 0 & 1 & 2 \\
\hline Dremomys & 0 & 0 & 0 & 0 & 0 & 3 \\
\hline Prosciurillus & 0 & 0 & 0 & 1 & 1 & 4 \\
\hline Sciurillus & 0 & 1 & 0 & 1 & 2 & 4 \\
\hline Sundasciurus & 0 & 0 & 0 & 0 & 0 & $3-4$ \\
\hline Petinomys & 1 & 1 & 0 & 1 & 3 & 3 \\
\hline Lariscus & 0 & 0 & 0 & 0 & 0 & $3-4$ \\
\hline Rubrisciurus & 0 & 0 & 0 & 1 & 1 & 4 \\
\hline Heliosciurus & 0 & 0 & 0 & 0 & 0 & 4 \\
\hline Rhinosciurus & 0 & 0 & 0 & 0 & 0 & $3-4$ \\
\hline Sciurotamias & 0 & 0 & 0 & 0 & 0 & 2 \\
\hline Epixerus & 0 & 0 & 0 & 0 & 0 & $3-4$ \\
\hline Exilisciurus & 0 & 0 & 0 & 0 & 0 & $3-4$ \\
\hline Glyphotes & 0 & 0 & 0 & 0 & 0 & 3 \\
\hline Hyosciurus & 0 & 0 & 0 & 0 & 0 & 4 \\
\hline Myosciurus & 0 & 0 & 0 & 0 & 0 & 3 \\
\hline Nannosciurus & 0 & 0 & 0 & 0 & 0 & 4 \\
\hline Protoxerus & 0 & 0 & 0 & 0 & 0 & $3-4$ \\
\hline Rheithrosciurus & 0 & 0 & 0 & 0 & 0 & $3-4$ \\
\hline Spermophilopsis & 0 & 0 & 0 & 0 & 0 & 2 \\
\hline
\end{tabular}


Table 1. Continued.

\begin{tabular}{lllllll}
\hline Genera & Ecology & Taxonomy & Biogeography & Conservation & Total no. of studies & Latitudinal bands \\
\hline Syntheosciurus & 0 & 0 & 0 & 0 & 0 & 3 \\
Aeretes & 0 & 0 & 0 & 0 & 0 & 2 \\
Aeromys & 0 & 0 & 0 & 0 & 0 & 3 \\
Biswamayopterus & 0 & 0 & 0 & 0 & 0 & 2 \\
Iomys & 0 & 0 & 0 & 0 & 0 & 4 \\
Petaurillus & 0 & 0 & 0 & 0 & 0 & $3-4$ \\
Pteromyscus & 0 & 0 & 0 & 0 & 0 & 2 \\
Eoglaucomys & 0 & 0 & 0 & 0 &
\end{tabular}

\section{Discussion}

This paper highlights two clear patterns. Firstly, Sciuridae follow the Rapoport's effect in that mean range size decreased substantially from temperate to tropical and equatorial regions. Secondly, there was an evident excess of studies published on temperate genera (characterized by wide range sizes) compared to equatorial and tropical genera (characterized by narrow range sizes).

Concerning point 1), it should be mentioned that in squirrels smaller values of mean range size are found in the genera present in the Neotropical region (marginal for Sciuridae), and in the Oriental and Palearctic regions, whereas the higher genera richness was observed in southeast Asia. At present it seems to be widely accepted that Rapoport's rule is a local phenomenon restricted to high latitudes in the northern Hemisphere (Rohde 1996, Gaston et al. 1998, Gaston and Chown 1999), whereas our study confirmed this effect also towards the Southern hemisphere. Thus, our data are in agreement with Cardillo's (2002) opinion that the pattern could be more general than is currently recognized. He found that the latitudinal range sizes of birds follow a latitudinal Rapoport effect at a global scale, although the pattern is not as strong in the southern hemisphere compared with the northern Hemisphere (but see Orme et al. 2006). Our study also showed that the Rapoport's effect was stronger in the northern than in the southern hemisphere, but we suggest that for Sciuridae this trend merely reflects the relative scarcity of genera in the southern hemisphere compared to the Northern hemisphere.

Concerning point 2), this pattern clearly reflects the different levels of funding available for scientific research in countries from the various latitudinal bands (these being concentrated especially in the USA and western Europe), but also the attitude of governmental and nongovernmental authorities to concentrate their research and conservation efforts preferentially towards the charismatic mammals in the tropics (Amori and Gippoliti 2000, 2003). Thus, there is a potentially serious gap between current knowledge and threat expectations for Sciuridae worldwide. This fact may be especially crucial as there are currently five highly threatened genera of Sciuridae, all being tropical (four Asian and one African) and six potentially threatened (also all tropical, five Asian and one African) (Amori and Gippoliti 2003).

In conclusion, by this study we would strongly urge governmental and non-governmental organizations, as well as scientists, to give priority attention in the years to come towards field studies of tropical Sciuridae genera. This is also important because nearly all tropical Sciuridae are linked to forest biota, that are currently under severe threat by agricultural exploitation, logging, and urban development (Raman et al. 2002, Rodrigues et al. 2004, Perry 2007).

Acknowledgements - We thank Dr Paul Williams (Natural History Museum) for providing a copy of his software World Map, and helping us with use of this software, Adriano Martinoli for helping with ISI web-based literature, and anonymous reviewers for constructive comments on the submitted version.

\section{References}

Amori, G. and Gippoliti, S. 2000. What do mammalogists want to save? Ten years of mammalian conservation biology. Biodiv. Conserv. 9: 785-793.

Amori, G. and Gippoliti, S. 2001. Identifying priority ecoregions for rodent conservation at the genus level. - Oryx 35: 158-165.

Amori, G. and Gippoliti, S. 2003. A higher-taxon approach to rodent conservation priorities for the 21 st century. - Anim. Biodiv. Conserv. 26: 1-18.

Amori, G. et al. 2009. Do interlinks between geography and ecology explain the latitudinal diversity patterns in Sciuridae? An approach at the genus level. - Can. J. Zool., in press.

Arita, H. T. et al. 1997. Geographical range size and the conservation of Mexican mammals. - Conserv. Biol. 11: 92100.

Baldi, A. 2003. Using higher taxa as surrogates of species richness: a study based on 3700 Coleoptera, Diptera, and Acari species in central-Hungarian reserves. - Basic Appl. Ecol. 4: 589-593. 
Blackburn, T. M. and Gaston, K. J. 2006. There's more to macroecology than meets the eye. - Global Ecol. Biogeogr. 15: 537-540.

Cardillo, M. 2002. The life-history basis of latitudinal diversity gradients: how do species traits vary from the poles to the equator? - J. Anim. Ecol. 71: 79-87.

Corbet, G. B. and Hill, J. E. 1992. The mammals of the Indomalayan Region. - Oxford Univ. Press.

Diniz-Filho, J. A. and Tôrres, N. M. 2002. Rapoport effect in South American Carnivora (Mammalia): null models under geometric and phylogenetic constraints. - Brazil. J. Biol. 62, doi: 10.1590/S1519-69842002000300006.

Eeley, H. A. C. and Foley, R. A. 1999. Species richness, species range size and ecological specialisation among African primates: geographical patterns and conservation implications. - Biodiv. Conserv. 8: 1033-1056.

Eisenberg, J. F. 1989. Mammals of the Neotropics. The northern Neotropics. - Univ. of Chicago Press.

Emmons, L. H. and Feer, F. 1990. Neotropical rainforest mammals. A field guide. - Univ. of Chicago Press.

Gaston, K. J. and Blackburn, T. M. 1996. Conservation implications of geographic range size-body size relationships. Conserv. Biol. 10: 638-646.

Gaston, K. J. and Chown, S. L. 1999. Why Rapoport's rule does not generalize. - Oikos 84: 309-312.

Gaston, K. J. et al. 1998. Rapoport's rule: time for an epitaph? Trends Ecol. Evol. 13: 70-74.

Gharaibeh, B. M. and Jones, C. 1996. Myosciurus pumilio. Mammal. Species 523: 1-3.

Gippoliti, S. and Amori, G. 2007. The problem of subspecies and biased taxonomy in conservation lists: the case of mammals. - Folia Zool. 56: 113-117.

Gotelli, N. J. and Entsminger, G. L. 2002. EcoSim: null models software for ecology, ver. 7.0. Acquired Intelligence and Kesey-Bear, Jericho, Vermont, USA, <http://homepages.together.net/;gentsmin/ecosim.htm>.

Graves, G. R. and Rahbek, C. 2005. Source pool geometry and the assembly of continental faunas. - Proc. Natl Acad. Sci. USA 102: 7871-7876.

Grubb, P. et al. 1998. Mammals of Ghana, Sierra Leone and the Gambia. - Trendrine Press, Zannor, U.K.

Hawkins, B. A. and Diniz-Filho, J. A. F. 2006. Beyond Rapoport's rule: evaluating range size patterns of New World birds in a two-dimensional framework. - Global Ecol. Biogeogr. 15: 461-469.

Kingdon, J. 1997. The Kingdon field guide to African Mammals. - Academic Press, San Diego.

La Ferla, B. et al. 2002. Continental scale patterns of biodiversity: can higher taxa accurately predict African plant distributions? - Bot. J. Linn. Soc. 138: 225-235.

Lyons, S. K. and Willig, M. R. 1997. Latitudinal patterns of range size: methodological concerns and empirical evaluations for New World bats and marsupials. - Oikos 79: 568-580.

Mace, G. M. et al. 2001. Assessment and management of species at risk. - In: Soulé, M. E. and Orians, G. H. (eds), Conservation biology: research priorities for the next decade. Island Press, pp. 11-29.

Noonan, G. R. 1999. GIS analysis of the biogeography of beetles of the subgenus Anisodactylus (Insecta: Coleoptera: Carabidae: genus Anisodactylus). - J. Biogeogr. 26: 1147-1160.
Orme, C. D. L. et al. 2006. Global patterns of geographic range size in birds. - PloS Biol. 4: 1276-1283.

Pagel, M. D. et al. 1991. Ecological aspects of the geographical distribution and diversity of mammalian species. - Am. Nat. 137: 791-815.

Panteleyev, P. A. 1998. The rodents of the Palearctic. - Russian Acad. Sci.

Perry, P. T. 2007. The moist tropical forest: its conversion and protection. - Environmentalist 2007: 117-132.

Powell, M. G. 2007. Latitudinal diversity gradients for brachiopod genera during late Palaeozoic time: links between climate, biogeography and evolutionary rates. - Global Ecol. Biogeogr. 16: 519-528

Rabenold, K. N. 1992. Latitudinal gradients in avian species diversity and the role of long-distance migration. - Curr. Ornithol. 10: 247-274.

Raman, T. et al. 2002. Responses of tropical rainforest birds to abandoned plantations, edges and logged forest in the western Ghats, India. - Anim. Conserv. 5: 201-216.

Reid, F. A. 1997. A field guide to the mammals of central America and southeast Mexico. - Oxford Univ. Press.

Ribas, C. R. and Schoereder, J. H. 2006. Is the Rapoport effect widespread? Null models revisited. - Global Ecol. Biogeogr. 15: 614-624.

Rodrigues, R. R. et al. 2004. Tropical rain forest regeneration in an area degraded by mining in Mato Grosso State, Brazil. For. Ecol. Manage. 190: 323-333.

Rohde, K. 1996. Rapoport's rule is a local phenomenon and cannot explain latitudinal gradients in species diversity. - Biodiv. Lett. 3: 10-13.

Rohde, K. et al. 1993. Rapoport's rule does not apply to marine teleosts and cannot explain latitudinal gradients in species richness. - Am. Nat. 142: 1-16.

Ruggiero, A. and Werenkraut, V. 2007. One-dimensional analyses of Rapoport's rule reviewed through meta-analysis. Global Ecol. Biogeogr. 2007: 1-14.

Smith, F. D. M. et al. 1994. Geographical ranges of Australian mammals. - J. Anim. Ecol. 63: 441-450.

Stevens, G. C. 1989. The latitudinal gradient in geographical range: how so many species coexist in the tropics. - Am. Nat. 133: 240-256.

Taylor, P. H. and Gaines, S. D. 1999. Can Rapoport's rule be rescued? Modelling causes of the latitudinal gradient in species richness. - Ecology 80: 2474-2482.

Thorington, R. W. et al. 1996. Validity of three genera of flying squirrels: Euglacomys, Glaucomys and Hylopetes. - J. Mammal. 77: 69-83.

Wells, N. M. and Giacalone, J. 1985. Syntheosciurus brochus. Mammal. Species 249: 1-3.

Williams, P. 2001. Worldmap Software. Natural History Museum, London.

Wilson, D. E. and Reeder, D. M. 2005. Mammal species of the world. A taxonomic and geographic reference (3rd ed.). John Hopkins Univ. Press.

Zahler, P. and Karim, A. 1998. New distribution, elevation, habitat, and diurnal refuge for the Kashmir flying squirrel Euglacomys fimbriatus. - Mammalia 62: 588-591. 